Michael T. Belongia is a research officer at the Federal Reserve

Bank of St. Louis. Anne M. Grubish provided research assistance.

\title{
Are Economic Forecasts by Government Agencies Biased?
} Accurate?

"The CBO's analyses and forecasts, while far from flawless, have come to be viewed as the best objective evidence that economists can muster. In stark contrast, everyone knows that Executive Branch estimates pass through many political filters."

Alan S. Blinder, Business Week

E often are tainted by allegations of political partisanship. Forecasts by the Council of Economic Advisers (CEA) for example, which represent the expected impacts of the President's economic policies, have been characterized as "rosy scenarios," that are too optimistic about the prospects for strong teal growth and lower unemployment. In recent years, even White House insiders have alleged that the ClA's numbers were "cooked" to portray favorable economic outcomes."

Congress has its own economic agency, the Congressional Budget Office (CBO), that also produces forecasts for real growth, unemployment and inflation on a timetable similat to that of the CEA. In contrast to the CEA, the CBO forecasts have been widely regarded as being accumate and objective. Still, they too have been criticized as biased or inaccurate, especially when the CFA and CBO outlooks have differed substantially:

With several U.S. government agencies making economic forecasts and allegations being raised about the relative merits of these altemative forecasts, a number of obvious questions arise. The purpose of this paper is to determine first whether economic forecasts made by the CEA and CBO have been biased. Then, because allegations of bias carry the implication of inaccuracy, the forecasts also are evaluated on this basis. Finally, to provide some apolitical benchmarks, the forecasts of several well-known private sector groups are examined for bias and accuracy.

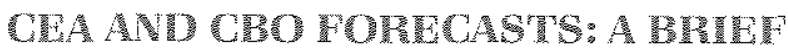

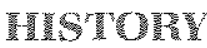

The Council of Economic Advises was established by the Employment Act of 1946. The Eco-
'The "rosy scenario" characterization of Reagan administration economic forecasts has been attributed to Stockman (1986). Smith (1988) reports comments from a number of observers who feel the CEA forecasts are biased. As a technical matter, it is more accurate to talk about "Administration" forecasts instead of "CEA" forecasts during the Reagan years. During this period the "troika" process involving the CEA, the Treasury Department, and the Office of Management and Budget (OMB) produced a consensus forecast not associated with the CEA independently.

ssee, for example, Meiselman and Roberts (1979). 


\section{Chart 1}

\section{CEA and CBO Real GNP Forecasts vs Actual GNP Growth}

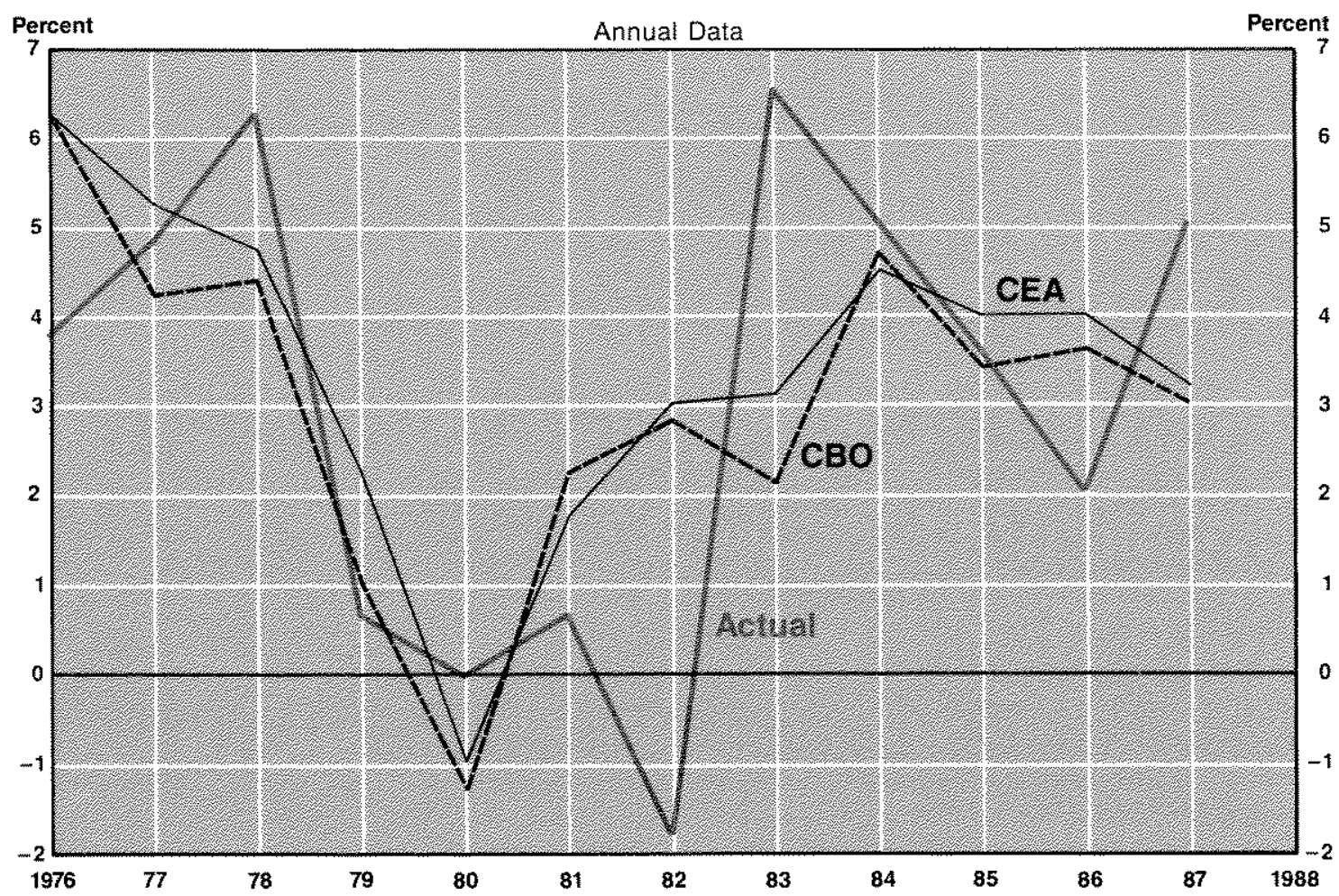

nomic Report of the President, which the CEA publishes annualy, includes a short essay by the President and a much longer report by the CEA staff; typically, it also includes an economic forecast for the year ahead. The forecasts in the Report can be regarded as true $e_{x}$ ante predictions because they are released in late January or February. well before any official economic data for the calendar year are reported.

The Congressional Budget Office was established in 1974 as part of the new budget process created by the Congressional Budget and Impoundment Control Act. The CBO was established to provide Congress "with detailed budget information and studies of the budget impact of alternative policies."'The CBO was created primarily to provide budget analyses and economic forecasts that are independent from those of the CEA and Office of Management and Budget $(\mathrm{OMB})$, both of which the President and Executive Branch con- trol. The CBO's forecasts are reported in its $\mathrm{Eco}$ nomic and Budget Outlook for Economic Outlook in earlier years!, which is released early in the calendar year.

Anmual CEA and CBO forecasts for real GNP growth, the inflation rate and the level of unemployment are plotted in charts $1-3$ for the period 1976-87. GNP and inflation values are fourthquarter-over-fourth-quarter rates of change. The unemployment rate shown is the fourth quarter level. Unemployment rate forecasts are generally the fourth-quarter level but, for the last five years of the CBO forecasts, the predictions represent the annual average unemployment rate.

Although the CEA has made economic forecasts since the late 1940s, the data plotted in the charts begin in 1976 for two reasons. First, the CBO's initial forecast was for the year 1976; thus, direct comparisons between the two series are limited to the post-1976 period. Second, before the early

U.S. Congress (1976), p. 1. For a detaited review of the CBO's creation and stated mission, see Meiselman and Roberts (1979) and the comments by De Leeuw, Phaup and Rivlin that follow their article. 
Chart 2

CEA and CBO Inflation Forecasts vs Actual GNP Inflation

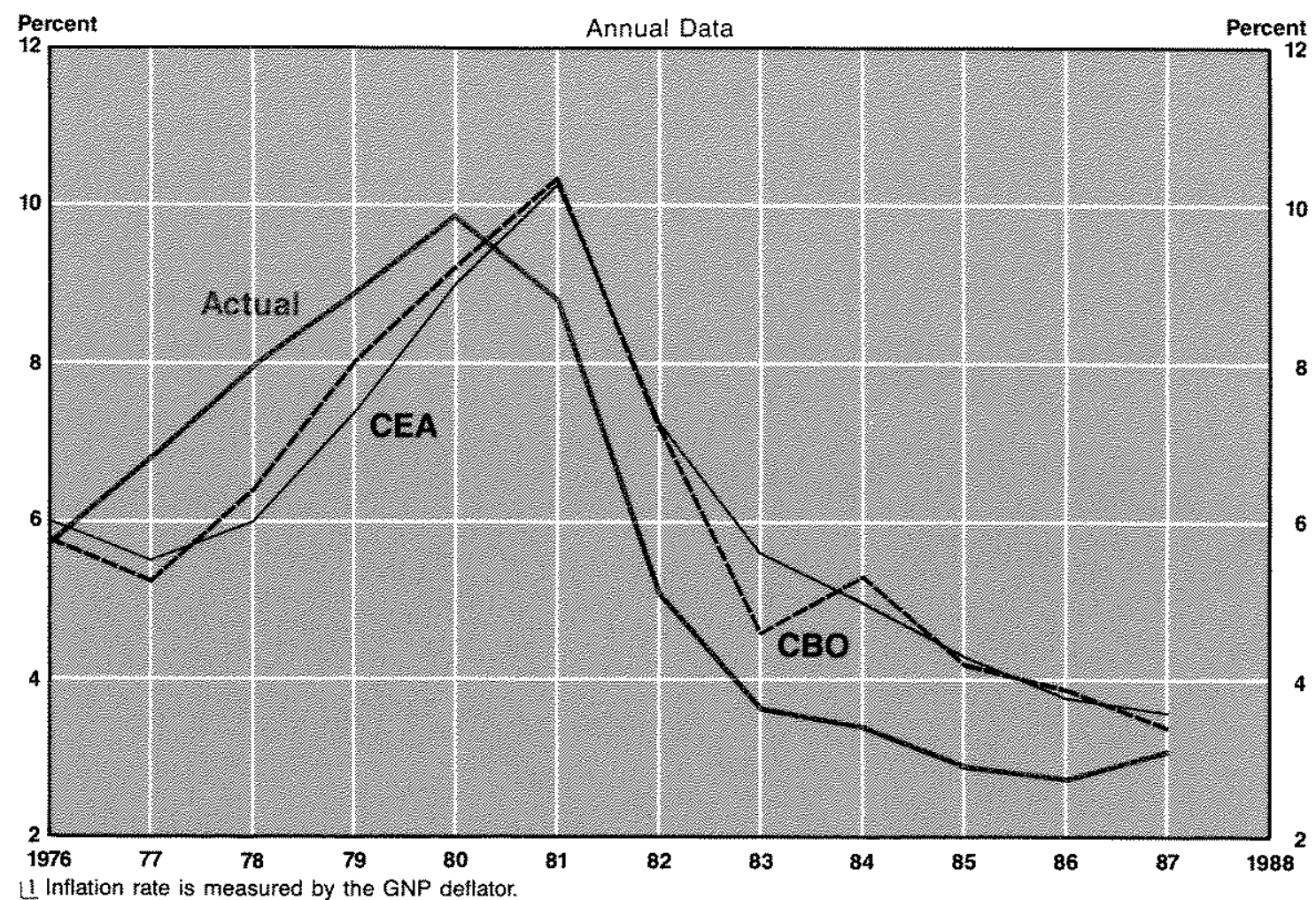

1970s, the CEA forecasts often were couched in qualitative terms (for example, "lower inflation" or "slightly faster growth"), which cannot be analyzed statistically, ${ }^{+}$

An inspection of the charts indicates that both sets of forecasts generally move in the same direction; the correspondence seems particularty close for the inflation forecasts. The GNP and unemployment forecasts, however, show some interesting variations. Since 1981, the CEA's forecasts of real growth have been generally higher than the CBO's. For the whole period CEA unemployment rate forecasts have been lower than the CBO's. These figures indicate that the CEA typically has forecast stronger real economic activity than the CBO. Whether these forecast differences represent a systematic bias of significant magnitude, by either the CEA or the CBO, requires further analysis."

\section{STATISTICAL ASSESSMENT OF PORECAST BIAS}

Figure 1 shows a conceptual framework with which to assess the relationships that might oecur if the actual values of a specific series were plotted against the values that had been predicted. If the forecasts were perfect - that is, if the forecast errors at each point in time were zero - a line relating the actual to the forecast values would have an intercept of zero and a slope of one; this line, denoted LPF in the figure, is what Mincer and Zarnowitz (1969) call the "line of perfect forecasts." Bias in a forecast merely indicates that the mean value of the actual series $(\bar{A})$ is not equal to the mean of the forecast series $(\tilde{\mathbf{P}})$ and, therefore, that the point $E$, determined by the ordered pair $(\bar{A}, \overline{\mathbf{P}})$, will not be on the LPF line." The extent of bias in
AMoore (1977) has constructed a CEA forecast series for the years $1962-76$ based on inferences from the text of the Economic Report of the President. See footnote 8 for further discussion of these earlier forecasts.

${ }^{5}$ Carlson (1982) also has evaluated CEA forecasts and, in the context of a monetarist model, found them to be internally inconsistent. an more technical terms, the mathematical expectation of the actual series, $E(A)$, is not equal to the expectation of the forecast series, E(P). See, for example, Mincer and Zarnowitz (1969), pp. 6-9. Webb (1987) provides further discussion of what is and is not leamed from tests for bias. 


\section{Chart 3 \\ CEA and CBO Unemployment Forecasts vs Actual Unemployment}

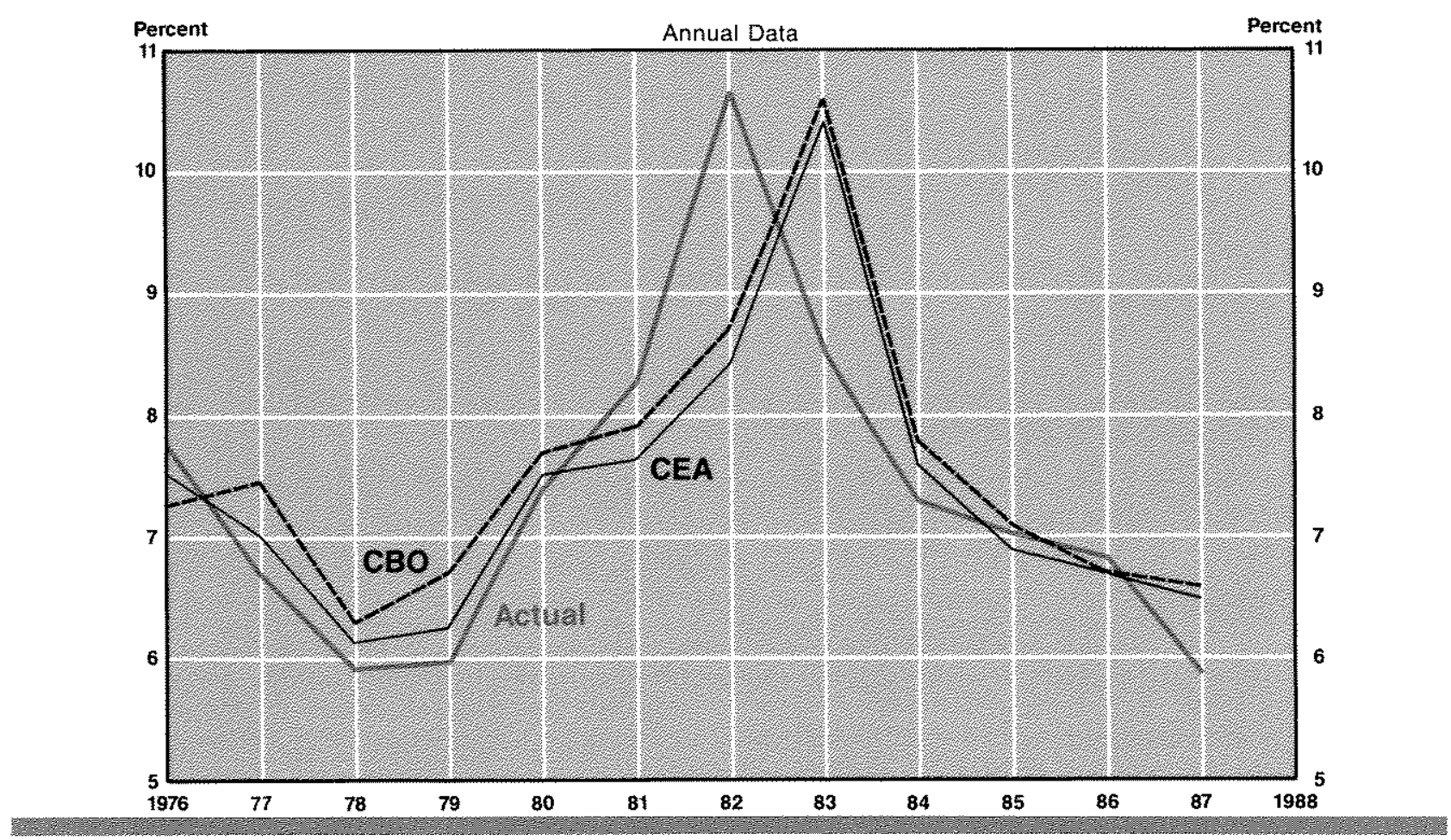

the forecast is depicted in figure 1 as the distance between a point on the LPF line and point $E$. which is defined by the means of the actual and forecast series.

In view of this discussion, a standard test for bias in a forecast can be constructed by estimating a regression of the form:

(1) $Y_{t}=a+b E\left(Y_{1}\right)+e_{13}$

where $Y_{\text {, }}$ is the actual value of a variable in period $t, E(Y)$ is its "predicted" or "forecast" value and $e_{\text {, }}$ is the forecast error lactual minus predicted value!. If the forecast is unbiased, the regression's intercept, a, should not be significantly different from zero and its slope coefficient, b, should not be significantly different from one; recall that these values for a and $b$ define the lup bine in figure 1 . If $a=0$ and $b=1$ in equation 1 , the actual and forecast values will differ only by random ertor, as represented by $e_{1}$. Moreover, the error would equal zeno, on average, over long periods of time.

The results of estimating regressions like equation 1 for the CEA and CBO forecasts of real GNP growth $\mid \dot{y})$, the inflation rate $(\dot{P})$ and unemployment rate $(U)$ over the $1976-87$ period are shown in table 1 . The important results for current pur" poses are the f-statistics corresponding to the null hypothesis that an equation's intercept term is equal to zero and its slope coefficient is equal to one. This hypothesis is not rejected for any of the six equations; none of the $F$-statistics is greater than 0.5 and the 5 percent critical value is 4.10 . Therefore irespective of forecast accuracy and
7 Some research in this line of work has asked which measure of the "actual" value should be used: the first-announced (unrevised) figure or the final (revised) value? Throughout, the final, revised figure is used. This choice is defended, logically, on the basis that this value, in fact, is what people are trying to forecast, even though it includes such unknowns as seasonat adjustments and benchmark tevisions. As a practical matter. estimates of equation 1 with first-annourced data had no qualitative effect on any of the results. McNees (1988) also has found that the choice of measure for actual values has little impact on annual forecasts, such as these, but apparently is important for quarterly forecasts. 


\section{Figure 1}

The Prediction-Realization Diagram

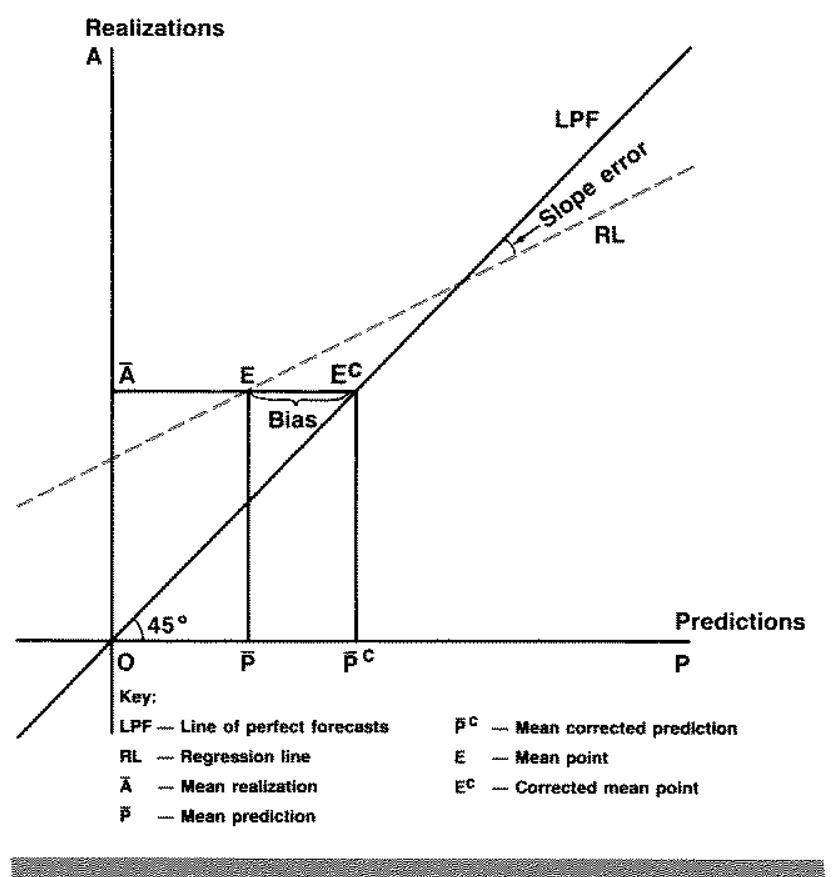

despite assertions to the contrary, both the CEA and CBO forecasts can be called unbiased."

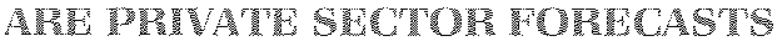 WIASTIV?}

The results in table 1 indicate that the forecasts of two government agencies are unbiased. Inbiasedness, however, is not unambiguously desirable if some bias is associated with greater forecast accuracy. Zellner (1986), for example, shows that a biased forecast is the optimal predictor under certain circumstances; Mincer and Zamowitz (1969) also noted this characteristic. Still, many obsevers associate bias with inaccuracy in a forecast. Is it possible instead that some other forecasts are biased, but more accurate than those of the CEA and CBO?

As a first step to investigate this possibility, the mean forecasts of a panel surveyed by the American Statistical Association and National Bureau of
Table 1

Bias Tests for CEA and CBO Forecasts

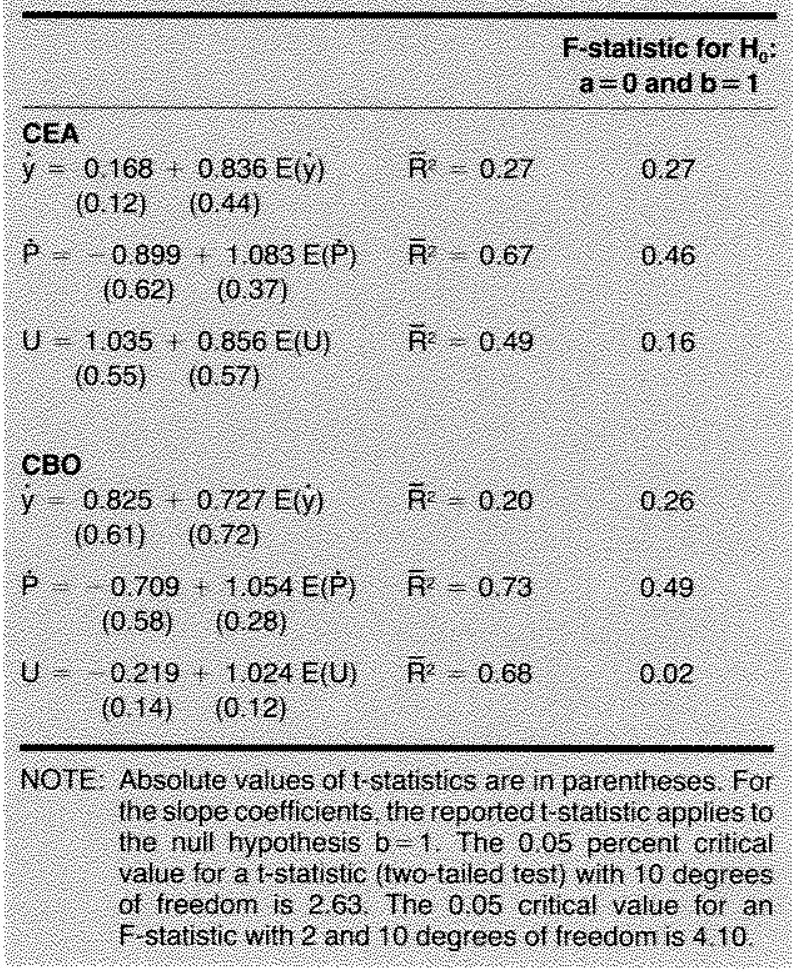

Economic Research $(A S A N B E R$ and the forecasts from the large econometric models of two wellknown consulting firms were evaluated by the same tests described earlier." To make these tests comparable with those already reported in table 1 data were examined duing the same 1976-87 interval for the forecasts published closest to the release dates of the CEA and CBO predictions; plots of actual vs. forecast values are shown in charts $4-6$. The bias tests for the private sector forecasts are reported in table 2 . The results do not indicate bias in the ASA NBER forecasts for any of the three variables examined. Moreover, explanatory power generally is higher for these equations than for the comparable CEA or CBO equations. The forecasts from the two consulting firms also exhibit no bias in any equation and generally have explanatory power comparable to that of the ASA NBER forecasts. Overall, the results in tables 1 and
Ift also is possible to evaluate CEA performance over a longer period. Moore (1977) has constructed a CEA forecast series back to 1962 for output and infiation, inferring quantitative estimates from the qualitative forecasts presented. Although this series is subject to error from such judgmental adjustn ments, the longer sample increases the power of the test statistics. The results of estimating equations such as equation 1 over the longer sample indicate bias in the inflation equation as the intercept is significantly greater than zero; this result suggests that the CEA, on average, has been overy optimistic about future inflation. No bias is evident in the GNP equation.

"Stephen McNees kindly provided these data. A condition for their use, however, was that the specific firms remain anonymous. Historical data on the economic torecasts of many alternative forecasters also was available (until 1986) in the Federal Reserve Bank of Richmond's Busmess Outlook. 
Chart 4

ASA/NBER, Firm A and Firm B Real GNP Forecasts vs Actual GNP Growth

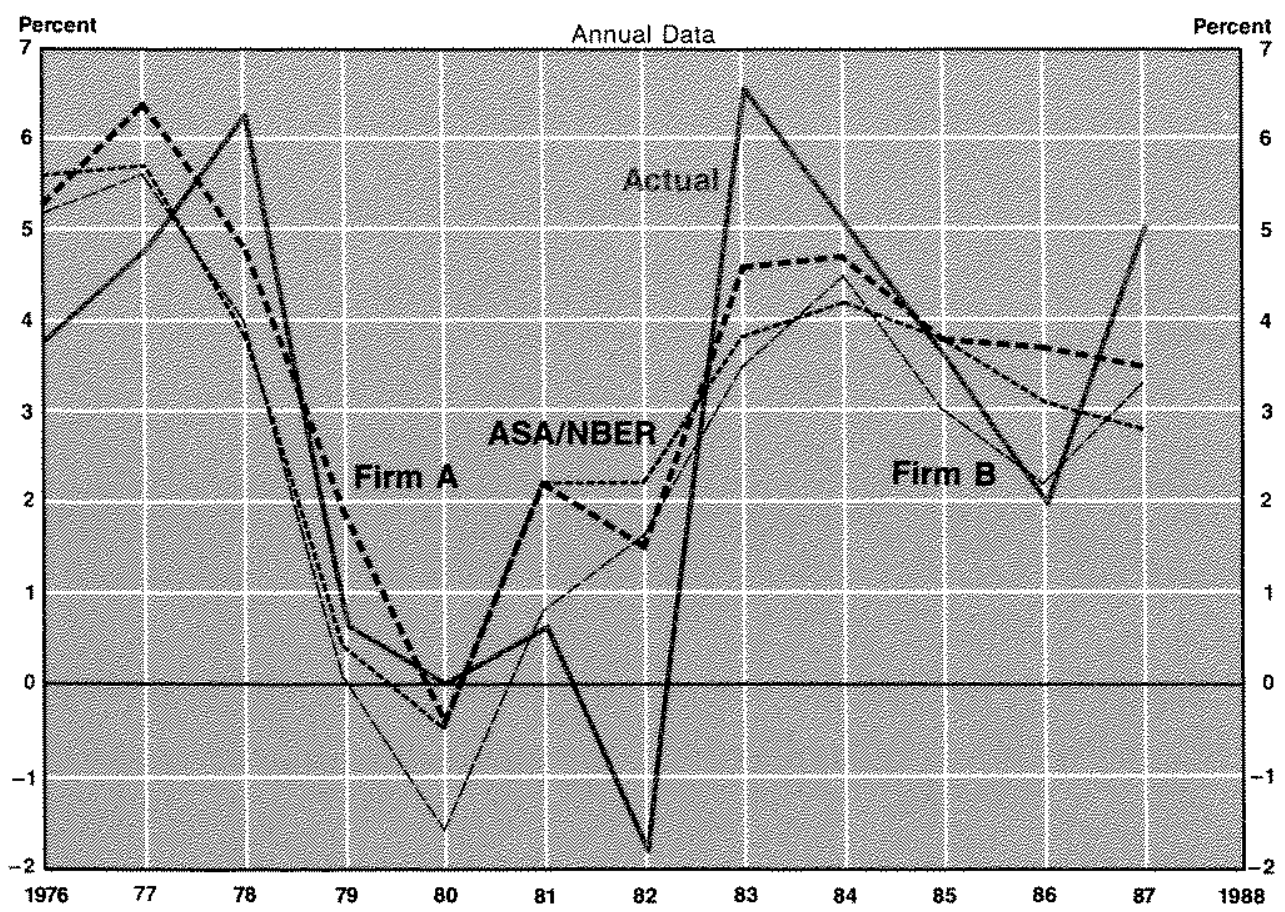

Chart 5

ASA/NBER, Firm A and Firm B Inflation Forecasts vs Actual Inflation ${ }^{13}$

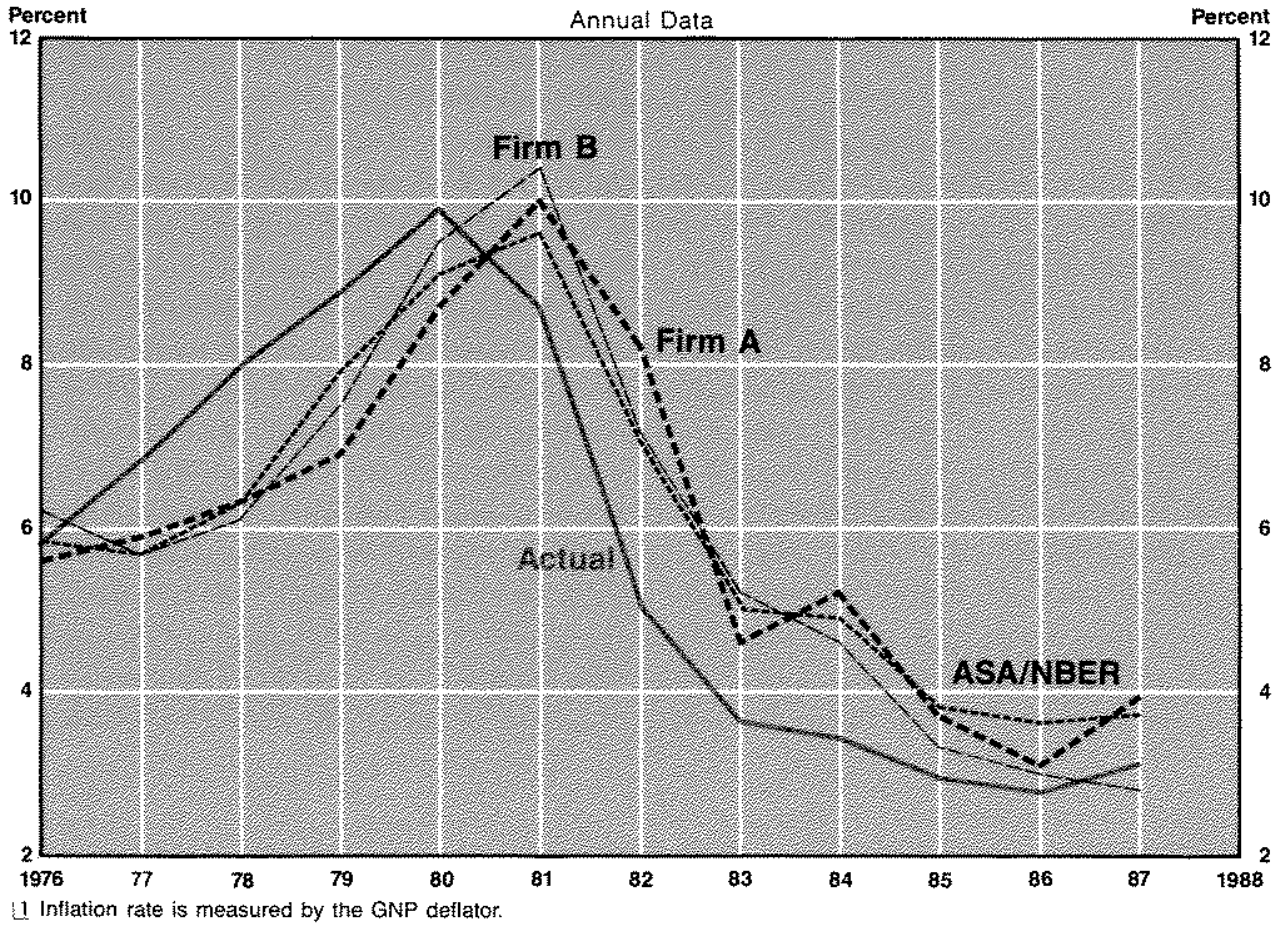




\section{Chart 6}

\section{ASA/NBER, Firm A and Firm B Unemployment Forecasts vs Actual Unemployment}

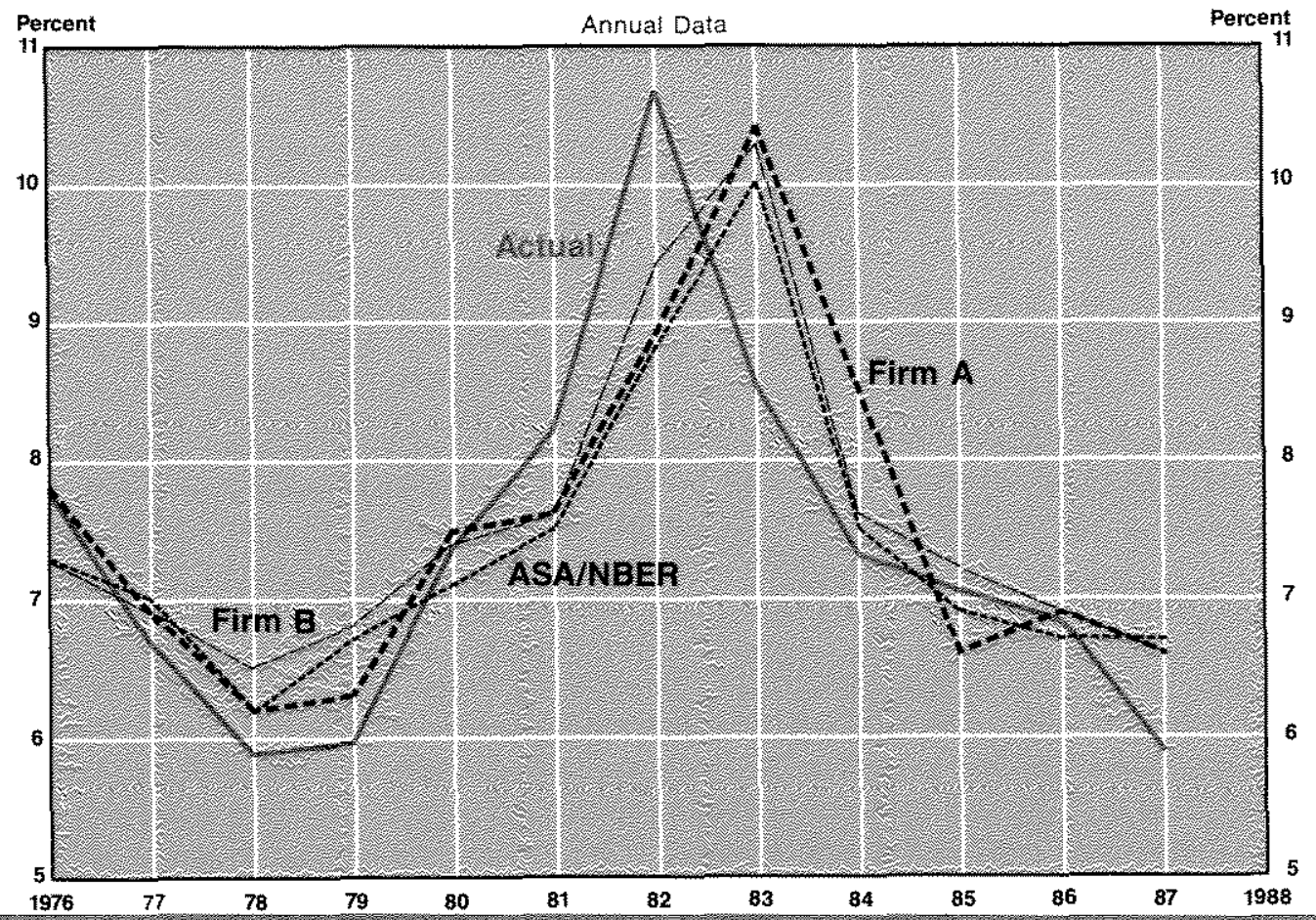

2 indicate that all five widely-cited forecasts of aggregate economic activity are unbiased.

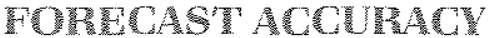

One way to compare the accuracy of alternative forecasts has been proposed by Fair and Shiller (1988). The test is performed by estimating a regression of the form:

$$
\begin{aligned}
& \text { (2) } Y_{t}-Y_{\mathrm{i}-\mathrm{s}}=\mathrm{a}+\mathrm{b}\left[_{1-\mathrm{S}} \mathrm{E}\left[\mathrm{Y}_{\mathrm{at}}\right\}-\mathrm{Y}_{1-\mathrm{n}}\right\} \\
& \left.+c \int_{1-s} \mathrm{E}_{1}\left(\mathrm{X}_{\mathrm{n}}\right]-\mathrm{Y}_{\mathrm{t}-\mathrm{s}}\right)+\mu_{\mathrm{s}}
\end{aligned}
$$

where $Y_{1}$ and $Y_{1-s}$ are the actual values of the variable being forecasted in periods $t$ and $t-s$, respectively, while ${ }_{-3} \mathrm{E}\left(\mathrm{Y}_{1}\right)$ and ${ }_{1-.} \mathrm{E}\left(\mathrm{Y}_{31}\right)$ are the predictions of forecasters \# 1 and \#2 at time $\mathrm{t}-\mathrm{s}$ for the value of $Y$ in period $t$. In this analysis, which uses annual data and one-year-ahead forecasts, $s$ is equal to one. If the predictions of either forecaster embodies information beyond the estimate of the one-period change represented by the regression's intercept tem, a, then one or both slope coefficients, $b$ and $c$ in equation 2, should be significantly different from zero. If CEA is forecaster \#1 and $b$ is significantly different from zero but $c$ is not, one concludes that the CEA forecast contains useful information and forecast \#2 has no information not contained in the CEA forecast. Finding c, but not b, significant would carry the opposite conclusion. Finding neither $b$ nor $c$ significant indicates that neither forecast has useful information beyond that contained in the intercept, which is interpreted as the average s-period change in Y."

These tests were performed for all pairs of the CEA, CBO, ASANBER, Firm $A$ and Firm $B$ forecasts of output, inflation and unemployment. As table 3 reports, a direct comparison of the $C E A$ and $C B O$ forecasts shows neither agency adds new information to the other's forecast of real GNP growth,
10That a simple extraction of past trends might be considered an alternative to "expert" forecasts has been suggested by analyses of forecast performance. Meltzer (1987a,b), for example, has shown that Federal Reserve forecasts were so imprecise that, predicting one quarter into the future, it was impossible to distinguist statistically between a forecast of strong real growth and recession. Another interesting result is reported by Strongin and Binkley (1988), who find that forecasts made late: in the year and incorporating more information than initial forecasts were as likely to deteriorate as to improve. 


\section{Table 2}

\section{Simple Bias Tests for Private Sector Forecasts}

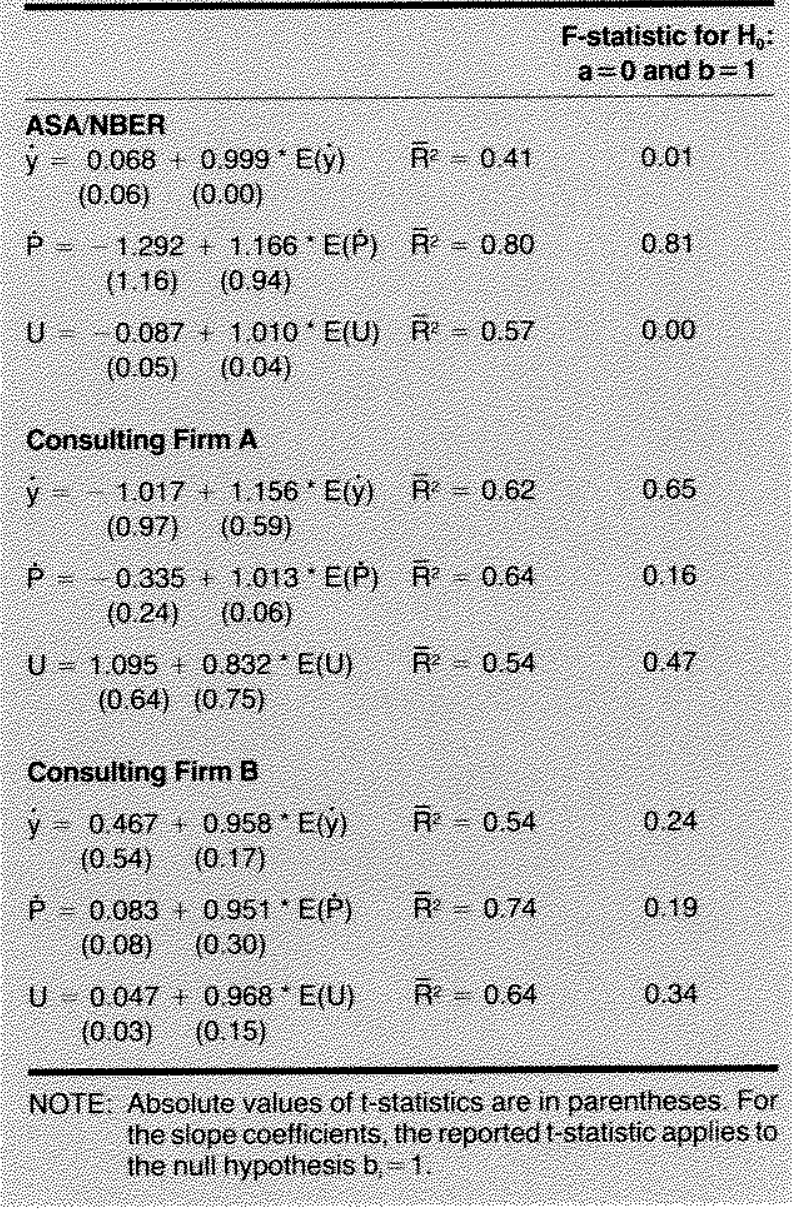

inflation of unemployment. Although this result is not surprising in view of the very similar regression results reported in table 1 , it also indicates there is no evidence to distinguish the forecasts of either agency as a better source of information.

When CEA forecasts are evaluated aganst the three private sector forecasts, a different picture emerges. When evaluated against the ASA/NBER survey, each institution's forecast for inflation adds to the information contained in the other and in the regression's intercept. Neither of their output or unemployment forecasts, however, adds to the information contained in the other. This evidence suggests that inflation forecasts can be improved by combining the information in the CEA and ASANBER forecasts. The comparisons with the two private sector firms, while offering a similarly mixed bag of results, generally indicate that, for real GNP and unemployment, Firm B ap-

\section{Table 3}

\section{Summary of Results from Fair-Shiller Tests}

\begin{tabular}{|c|c|c|c|}
\hline recast paif & & Intation & 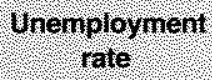 \\
\hline 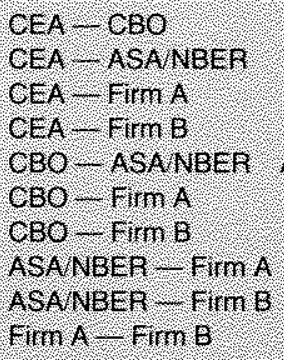 & 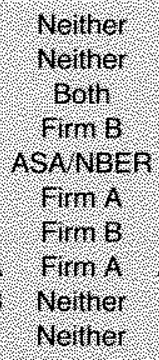 & $\begin{array}{l}\text { Neither } \\
\text { Boin. } \\
\text { neither } \\
\text { Neiher } \\
\text { Neither } \\
\text { Neither } \\
\text { Neither } \\
\text { A SAliber } \\
\text { Neither } \\
\text { Neither }\end{array}$ & Werner \\
\hline \multicolumn{4}{|c|}{ 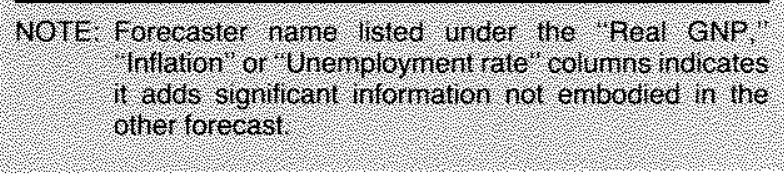 } \\
\hline
\end{tabular}

pears to offer additional information to the CEA's forecasts.

For the $\mathrm{CBO}$, the results suggest that any of the three private sector alternatives adds information to $\mathrm{CBO}^{\prime}$ s output forecast; two of the three also add information to the CBO's unemployment forecast. For inflation, however, there appear to be few gains from looking at the alternative forecasts. Among the three private sector firms, none of the results shows one to be superior to the others. Overall, the results in table 3 generally indicate that the private sector forecasts add to the information in the CBO forecasts while, aside from Firm B's contributions, the CEA and private forecasts contain similar information.

\section{CONCLUSIONS}

Members of both political parties sometimes allege that economic forecasts by govemment agencies are biased. An examination of this issue indicates that neither the CFA nor CBO forecasts exhibit any discernable bias. An evaluation of three private sector forecasts also detected no forecast bias. Absence of bias, however, does not necessarily indicate that a forecast is better (specifically mone accuratel. When three private sector forecasts were compared with $\mathrm{CEA}$ and $\mathrm{CBO}$ forecasts, however, the private sector forecasts generally were more accurate than those of the CBO; the CEA fared less well only relative to the forecasts of private sector Firm $B$. 


\section{MEDERECES}

Btinder, Alan S. "Dithering on Hill is Crippling a Key Agency," Business Week (September 26, 1988), p. 25.

Carlson, Keith. "A Monetary Analysis of the Administration's Budget and Economic Projections," this Review (May 1982), pp. 3-14.

Fair, Ray C., and Robert J. Shiller. "The Informational Content of Ex Ante Forecasts," Working Paper No. 2503 (National Bureau of Economic Research, February 1988).

McNees, Stephen K. "How Accurate Are Macroeconomic Forecasts?," New England Economic Review (July/August 1988), pp. 15-36.

Meiselman, David, and Paul Craig Roberts. "The Polttical Economy of the Congressional Budget Office," in Karl Brunner and Allan H. Melizer, eds., Three Aspects of Policymaking: Knowledge, Data and institutions, Carnegle-Rochester Conference Series on Public Policy, Vol. $10,(1979)$, pp. 283-333.

Mettzer, Allan H. "Limits of Short-Run Stabitization Policy." Economic inquiry (January 1987a), pp, 1-14.

"On Monetary Stability and Monetary Reform," Bank of Japan Monetary and Economic Studies (September 1987 b), pp. 13-34.
Mincer, Jacob, and Victor Zarnowitz. "The Evaluation of Economic Forecasts." in Jacob Mincer, ed., Economic Forecasts and Expectations, (National Bureau of Economic Research and Columbia University Press, 1969).

Moore, Geoffrey H. "The President's Economic Report: A Forecasting Record," NBER Feporter (April 1977), pp. 4-12

Smith, Hedrick. The Power Game (Random House, 1988)

Stockman, David. The Triumph of Politics (Harper and Row, Inc., 1986).

Strongin, Steven, and Paula S. Binkley. "A Poltcymaker's Guide to Economic Forecasts, "Federal Reserve Bank of Chicago Economic Perspectives (May/June 1988), pp. 3-10

U.S. Congress. The Congressional Budget Office Responsibifities and Organization (U.S. Government Printing Office, 1976).

Webb, Roy H. "The Irrelevance of Jests for Bias in Series of Macroeconomic Forecasts:" Federal Reserve Bank of Richmond Economic Review (November/December 1987). pp. 3-9.

Zellner, Arnold. "Biased Predictors, Rationality and the Evaluation of Forecasts." Economics Letters (No. 1, 1986), pp. $45-48$. 